\title{
Perceptions and practices of smokeless tobacco use in the form of mishri among rural women above 10 years of age in Pune, Maharashtra, India
}

\section{Vandana A. Kakrani, Priya Y. Kulkarni, Devidas T. Khedkar, Jitendra S. Bhawalkar \\ Department of Community Medicine, Dr. D. Y. Patil Medical College, Pimpri, Pune, Maharashtra, India}

Address for the Correspondence: Dr. Priya Y. Kulkarni, 5, Shanti Sadan, Erandawane, Pune, Maharashtra, India. E-mail:dr_pdkulkarni@ yahoo.co.in

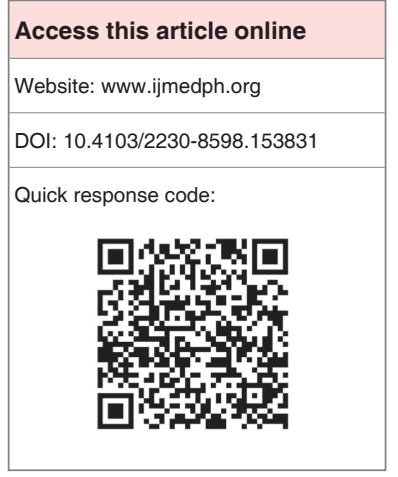

Background: Tobacco use in different forms has become a growing public health problem. It contributes to increased non communicable disease burden. Females tend to use smokeless tobacco in various forms. Material and methods: It was a cross sectional study conducted in the field practice area of Rural Health Training Centre of Dr. D Y Patil Medical College, Pimpri, Pune. Pretested, semistructured proforma was used to collect the information regarding the age of initiation and reasons for its use and other parameters of mishri use after taking informed consent from women $>10$ years of age. At the end of the study all the subjects were given active education in group setting. Results: Total 256 rural women were studied. $59.8 \%$ were $<45$ yrs, majority were Hindu, married and housewives. $50.4 \%$ belonged to joint families, $46.1 \%$ from nuclear families. Majority (55\%) were from socioeconomic class II and III. $38 \%$ initiated its use from 11 to $20 \mathrm{yrs}, 49 \%$ left it on teeth for a duration of less than 5 minutes, $38 \%$ of them used the amount as 1 tsf per day while another $37 \%$ used the amount as 1-2 tsf of mishri per day. $45.3 \%$ gave reasons for initiation of mishri as to clean teeth. Reasons for continuing use were noted as experienced a kick, gave energy, relieved tension, etc. Positive correlation was observed between quantity of mishri used at a single time and age as well as with duration of use ( $r=0.258, P<0.001$ and $r=0.335, P<0.001$ respectively). Conclusion: There is a need to make the rural women aware about hazardous effects of use of mishri through health education sessions to wean them out of this addiction.

Key words: Mishri, risk factors for noncommunicable diseases, tobacco

\section{INTRODUCTION}

Tobacco use is the single most preventable cause of death and disease among adults. ${ }^{[1]}$ Worldwide, almost six million people die each year due to tobacco related diseases including exposure to second hand smoke. ${ }^{[1]}$ Tobacco use in different forms has become a growing public health problem. ${ }^{[2]}$ It is a major risk factor for noncommunicable diseases like oral cancers, lung cancer circulatory diseases and stroke.... ${ }^{[2]}$ Though primarily a habit and addiction in men, it is estimated that nearly 250 million women in the world use tobacco daily. ${ }^{[3]}$

Smokeless tobacco is also very common in India. These are tobacco or tobacco-containing products which are chewed or sucked as a quid, or applied to gums, or inhaled. Some forms of smokeless tobacco like Gutkha are very popular in children and teenagers and their proportion is on rise. ${ }^{[4]}$ Smokeless tobacco in the form of mishri, gudakhu and toothpastes are popular because of the myth among population that tobacco in the product is a germicidal chemical and helps in cleaning teeth.

Mishri is prepared by roasting tobacco leaves. Its principal constituent is an alkaloid nicotine in $1-7 \%$. The roasted tobacco leaves are powered and it is known by various names like "Mishri," "Masherior," "Misheri." It is mainly a homemade preparation, but is also available in the market under different names. Mishri users often become addicted and start applying it as pastime. Due to rigid customs of society, smoking in women is uncommon. But, use of smokeless tobacco like Jarda, Khaini, Mishri is on increase 
specially among females in SEAR. ${ }^{[4-6]}$ Mishri use has become common in women in urban slums and rural area. As its use involve, direct application of tobacco to the gums, it increases the risk of cancer of the gums ${ }^{[7]}$ along with other health hazards of use of tobacco about which women using it may not be aware. ${ }^{[7]}$

Therefore, we conducted a study in Alandi which is a field practice area of Rural Health Training Centre (RHTC) of Dr D Y Patil Medical College, Pimpri, Pune catering to population of around 40,000 with an objective to assess perception and practices about mishri use in rural women.

\section{MATERIALS AND METHODS}

A cross-sectional descriptive study was conducted in the field practice area of RHTC of Dr D Y Patil Medical College, Pimpri, Pune over the period of 3 months during June 2013 to August 2013. Ethical clearance was obtained from the Institutional Ethics Committee of Dr D Y Patil Medical College, Hospital and research Centre before initiating the study.

All the women aged 10 years and above, using mishri, available at home on the day of survey were included in the study after informed consent. If the age of study subject was 10-18 years, informed consent was taken from parents or guardian.

As we did not find any proportion of rural mishri using women who had some perception about its adverse effects, in the literature or from previous studies in the same area, we conducted a pilot study among 22 mishri users in study area. Of them 5 had some perception about its adverse effect but they said it was OK for them.

So, sample size was calculated using PRIMER software (McGraw Hill, version 5.0.0.0) assuming $25 \%$ of study population had some perception about adverse health effects of mishri. Taking allowable error as $5 \%$ and power of the study $80 \%$, sample size came out to be 249 . Considering $5 \%$ refusals, we decided to enroll 265 females using mishri.

A home to home survey was carried out following a method of systematic random sampling. Starting from randomly selected first house every $6^{\text {th }}$ house was selected and asked for a women 10 years and above who is currently using mishri. If a female/females available using mishri in a household at the time of survey, she was/they were interviewed by trained interviewer. If study subject was not available at home at the time of interview, it was not visited again and next household was asked for. If any study subject denied to carry out interview, she was excluded from the study.

A pretested questionnaire was used to collect the data, which was previously validated in a pilot study. It was designed to get information regarding age of initiation of mishri use, its reasons, frequency, quantity, duration and type of mishri used, factors triggering its use and continuation along with sociodemographic information of the women respondent. To calculate per capita income, total members in family and total income of family per month was asked as per questionnaire.

These women were also asked whether they are aware about the harmful effects of its use, especially if they continued its use during pregnancy.

A team of 10 internees was trained by principal investigator of the study to interview the study subjects. If, a household did not have a female using mishri, subsequent $6^{\text {th }}$ house was selected and enquired till we got desired sample size.

At the end of the study, all the subjects were given health education in group setting with an interactive session if required referral was done to experts for advice on its cessation.

The data collected was entered into Microsoft Excel and was imported in the data editor using SPSS 15.0 designed by IBM, USA for further analysis. Frequencies were established for important sociodemographic characteristics. Appropriate tests of significance were used to assess any association between sociodemographic characteristics and parameters of mishri use. Two-tailed pearson's coefficient test was used to assess any co-relation between various parameters of mishri use like age at which use was started, duration and quantity of its use, monthly expenditure and co-relates like age, education, per capita income, total family members as shown in Table 1.

\begin{tabular}{|c|c|c|c|}
\hline Parameter of mishri use & Correlate & Correlation coefficient & $P$ \\
\hline \multirow[t]{3}{*}{ Age at which mishri use was started } & Per capita income & 0.175 & 0.006 \\
\hline & Total number of family members & 0.184 & 0.004 \\
\hline & Money spent on purchase per month & -0.162 & 0.011 \\
\hline \multirow{4}{*}{ Duration of use at a single time } & Age & 0.168 & 0.007 \\
\hline & Per capita income & -0.180 & 0.005 \\
\hline & Age at which mishri use was started & 0.130 & 0.037 \\
\hline & Quantity used at single time & 0.335 & $<0.0001$ \\
\hline \multirow[t]{4}{*}{ Quantity used at single time } & Age & 0.258 & $<0.0001$ \\
\hline & Education & -0.161 & 0.011 \\
\hline & Total family income & -0.202 & 0.01 \\
\hline & Duration of use at a single time & 0.335 & $<0.0001$ \\
\hline \multirow[t]{2}{*}{ Money spent on purchase per month } & Age at which mishri use was started & -0.162 & 0.011 \\
\hline & Age in years & -0.221 & $<0.0001$ \\
\hline
\end{tabular}




\section{RESULTS}

Totally 265 study subjects were enrolled, out of them three refused for totally, and six refused in the midst of the interview. Hence, we included total 256 rural women in the study.

\section{Sociodemographic characteristics}

Mean age of the study subjects was 43.63 years $(+14.258,15-83)$. Majority, $85.1 \%(186 / 254)$ belonged to $25-64$ years age group. Of 256, 91.8\% (235/256) females were married, 50.4\% (129/256) belonged to joint family, $46.1 \%(118 / 256)$ belonged to nuclear family and mean number of family members was 4.89 (+1.909). $35.2 \%(90 / 256)$ were illiterate, $25.8 \%(66 / 256)$ had either highschool certificate or educated above that. Housewives were $80.9 \%$ $(207 / 256)$ and very few, $1.6 \%$ (4/256) were employed in a skilled occupation [Table 2]. Mean per capita income was INR 2816.11 (+2531.83, 200-15,500). Total family income ranged from INR 1000 to INR 54,000/month. Median was INR 9000.

\section{Mishri consumption}

Females in the present study spent mean $92.75(+89.374,5-900)$ rupees per month to purchase mishri. Majority, 65.6\% (168/256) used readymade form. Use of readymade form was significantly lower among Buddhist than Hindus and Muslims, observed that they preferred roasted form (10/30 vs. 158/226; $P<0.001)$ while housewives were significantly more to use readymade form than employed females $(69.9 \%$ vs. $48 \%$; $P=0.003)$. Proportion of females

\begin{tabular}{|c|c|}
\hline Characteristics & Use mishri $n(\%)$ \\
\hline \multicolumn{2}{|l|}{ Age } \\
\hline$\leq 45$ & $153(59.8)$ \\
\hline$>45$ & 103 \\
\hline \multirow[t]{3}{*}{ Religion } & 220 \\
\hline & 30 \\
\hline & 6 \\
\hline \multirow[t]{4}{*}{ Occupation } & 207 \\
\hline & 35 \\
\hline & 10 \\
\hline & 4 \\
\hline \multirow[t]{4}{*}{ Marital status } & 235 \\
\hline & 7 \\
\hline & 5 \\
\hline & 2 \\
\hline \multirow[t]{3}{*}{ Type of family } & 129 \\
\hline & 118 \\
\hline & 9 \\
\hline \multirow[t]{5}{*}{ Socioeconomic class ${ }^{*}$} & 27 \\
\hline & 60 \\
\hline & 82 \\
\hline & 73 \\
\hline & 14 \\
\hline
\end{tabular}

*According to modified Prasad's classification for the year 2013 when data collection was done who used home-made roasted was significantly more to use it for $>5$ min at a time than females who used readymade forms $(P=0.036)$. Few of them, 3.5\% (9/256) used other form of tobacco with mishri.

Majority (69.5\%) had a habit of massaging gums while applying mishri on teeth. It was not associated with education, occupation, marital status type of family or religion.

\section{Duration and quantity of mishri consumption}

When enquired about the age at which women started using mishri, it was found that $38 \%$ initiated its use from 11 to 20 years, but around $31 \%$ started the use of mishri even below 10 years of age [Figure 1].

About, 30.5\% (78/256) started to use mishri since the age $<10$ years while $8.2 \%(31 / 256)$ used it for from the age of $>31$ years.

Years of consumption of mishri were positively correlated with total family income, number of family members, per capita income, duration of use at a time in minutes, money spent for purchase per month [Table 1]. Thus, as years of mishri use increased, duration of mishri use at a time increased. And, as same was observed for per capita income.

About $49 \%$ study subjects left mishri on teeth for a duration of $<5 \mathrm{~min}$ (and others kept it leisurely up to $5 \mathrm{~min}$ and some even more than that $(40 \%)$ [Figure 2].

Duration of use was positively correlated with years of using mishri, age and frequency/quantity of using it per day while negatively correlated with total family income, per capita income.

About $38 \%$ of them used the amount as 1 tea spoon full per day while another $37 \%$ used the amount as $1-2$ tsf of mishri per day [Figure 3]. Quantity of mishri used at a time had positive correlation with age and duration of use at a time, while negative correlation with education and total family income.

\section{Reasons for initiation and continuation}

In Table 3, the reasons for initiation of mishri were found to be cleaning of teeth in $45 \%(116 / 256), 13 \%$ (34/256) used it as other

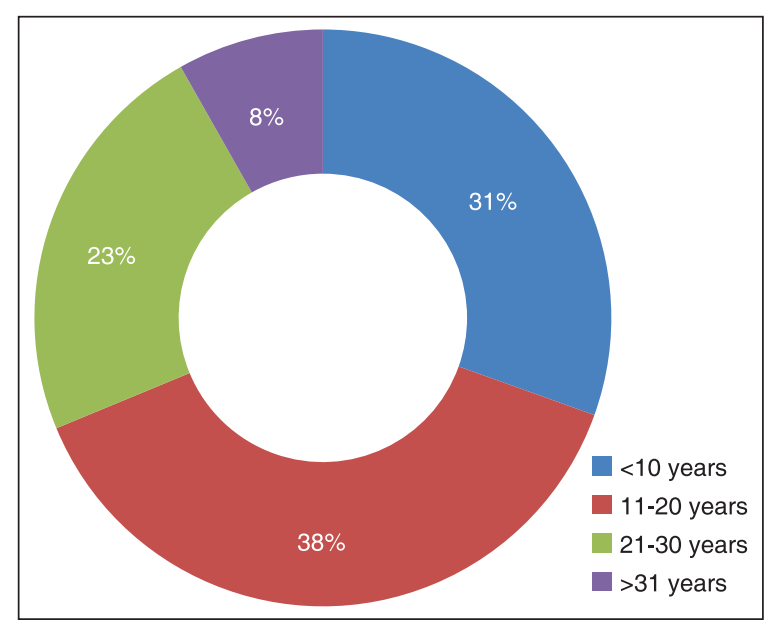

Figure 1: Age at which study subjects started to use Mishri 


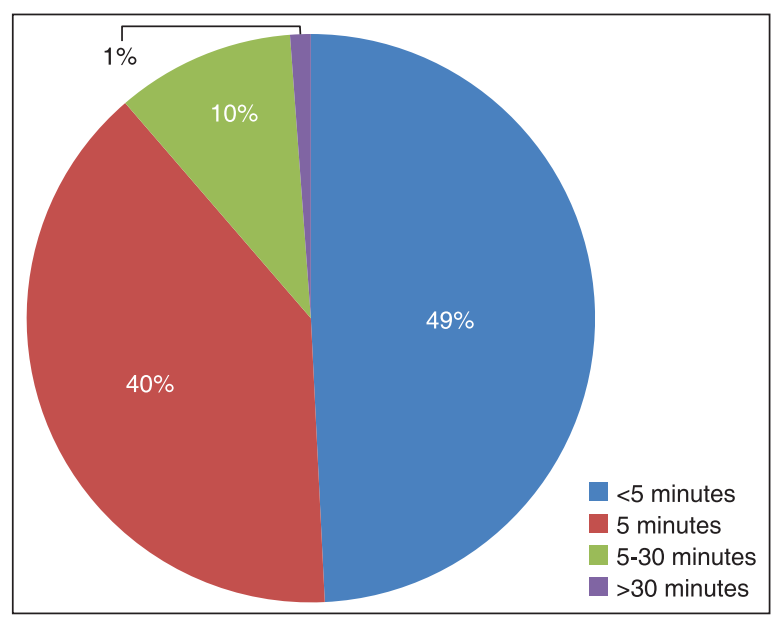

Figure 2: Duration of use of Mishri

family members used it, 15\% used it as friends were using it. Few, $13 \%$ used it to relieve toothache.

In Table 4 nearly about $17 \%$ (43/256) felt that its use gave them energy and experienced a kick, $12.89 \%(33 / 256)$ felt that it relieved their tension, while another $20 \%$ (50/256) were using it as time pass activity.

$45 \%(116 / 256)$ females admitted that they need to be continued to use mishri due to habit or addiction. Multiple reasons for the continuation were noted in $8 \%(21 / 256)$ females like to get energy and to relieve tension etc [Table 4].

\section{Knowledge about harmful effects of mishri}

Their knowledge about the harmful effects of this tobacco product was asked which revealed that $43.7 \%(112 / 256)$ were not aware that it was harmful to use mishri, while $3 \%(8 / 256)$ knew that it is harmful, but did not know any exact effects, which may be causing harm to them. Those who were aware of the harmful effects felt that its use can be responsible for oral cancer (38.6\%), acidity (13.28\%), hypertension (2.34\%) and peptic ulcer (1.56\%) [Table 5].

\section{Correlation between various parameters of mishri use}

When the correlation between the important variables was tested it revealed that age at which mishri use was started was positively correlated with per capita income, money spent on purchase per month and total family members [Table 1]. Similarly, quantity used at a single time was positively co-related with age thus it increased as age increased and negatively co-related with education. Furthermore, as quantity of mishri used at a single time increased, duration of use also increased $(r=0.335, P<0.001)$ [Table 1].

\section{DISCUSSION}

Tobacco use in various forms has reached alarming proportions in various communities. Unadulterated tobacco contains $>2500$ identified constituents, they include habit forming nicotine alkaloids, alkanes, terpines, poly phenols, phyto sterols. It also contains at least 30 metallic compounds, a large number of alcohols, aldehydes,

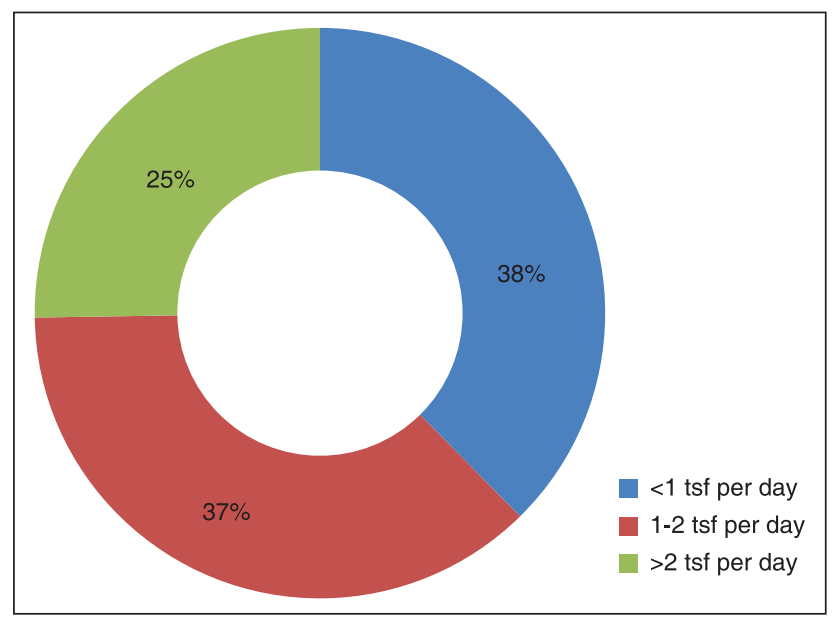

Figure 3: Quantity of misri used per day

\section{Table 3: Reasons for initiation to use mishri}

\begin{tabular}{lc}
\hline Reasons & Number (\%) \\
\hline Cleaning of teeth & $116(45.3)$ \\
Family members used it & 34 \\
Friends used it & 38 \\
Neighbors used it & 23 \\
To relieve toothache & 34 \\
Other reasons & 31 \\
\hline
\end{tabular}

*92.97\% (238/256) gave single reason, 7.03 (18/256) gave multiple reasons

\section{Table 4: Reasons to continue use of mishri}

\begin{tabular}{lcc}
\hline Reasons & Frequency & Percentage \\
\hline To get energy & 43 & 16.80 \\
To get kick & 14 & 5.47 \\
To relieve tension & 33 & 12.89 \\
Realized it as habit & 14 & 5.47 \\
For time pass & 50 & 19.53 \\
Other & 7 & 2.73 \\
\hline
\end{tabular}

* $91.80 \%(235 / 256)$ gave single reason, $8.20 \%$ (21/256) gave multiple reasons

\begin{tabular}{lc}
$\begin{array}{l}\text { Table 5: Awareness about harmful effects } \\
\text { of tobacco product consumption }\end{array}$ \\
\hline Awareness & Number $(\%)$ \\
\hline No any awareness & $112(43.7)$ \\
Knew that its harmful, but couldn't tell exact effects & $8(3.13)$ \\
Knew some harmful effects as & \\
Hypertension & 6 \\
IHD & 2 \\
Peptic ulcer & 4 \\
Acidity & 34 \\
Oral ulcers/cancer & 99 \\
Low birth weight babies & 2 \\
\hline
\end{tabular}

${ }^{*} 50 \%(128 / 256)$ knew single harmful effect, $7.42 \%$ (19/256) knew multiple side effects. IHD = Ischemic heart disease

ketones, heterocyclic compounds ${ }^{[8]}$ An analysis of mishri showed $99-2.4 \%$ nicotine and $14-32 \%$ ash in varying proportions in homemade or commercial preparations. It being pyrolysed tobacco powder is known to contain potent carcinogens like poly aromatic hydrocarbons. ${ }^{[9]}$ 
In a hospital based study, proportions of mishri use among women visiting antenatal clinic was $47 \%$, of which $62 \%$ were using it for $>10$ years. $^{[10]}$

In central and southern part of India, proportion of women using mishri, as teeth cleaning powder prepared by roasting tobacco leaves is quite high, in Mumbai up to $56 \%$ of women chew tobacco in pan. ${ }^{[11,12]}$

Various studies have estimated the prevalence of the use of mishri from $17 \%$ to $45 \% \cdot{ }^{[13-17]}$

The high proportion of mishri use in women could be attributed to the social sanction given to mishri use as a teeth cleaning powder. The women start using mishri at quite early age like $11-20$ years as in our study. The habit seems to be passed from one generation to the next as a tradition, as other workers also have noticed its use even in children, and the peak at which smokeless tobacco consumption is observed is either around $30-40$ years or after 50 years. ${ }^{[18,19]}$

The amount used in majority is almost one tea spoon full every time (fig), which is applied on teeth and gums for a period of about $5 \mathrm{~min}$ (fig), followed by gum massaging resulting in more amount of nicotine getting absorbed by the body..$^{[12,13]}$

This practice is common among women in a particular neighborhood due to peer pressure for its use. In our study [Table 3] also women started using mishri due to either family tradition of its use as teeth cleaning powder $(45.3 \%)$ or friends using it $(14.8 \%)$ some have used it to relieve toothache $(13.2 \%)$ The Native Americans used tobacco to clean teeth and relieve toothache, reported in a study where smokeless tobacco is observed to be a re-emerging menace. ${ }^{[20]}$

The addictive effect in the form of physical and emotional dependence of nicotine is known which makes the women continue its use after initiation, as they reported that they feel energetic or get relief from stress if used regularly. Some researchers have reported its association with menstrual phases, and observed that intake of nicotine is more in luteal phase than in follicular phase as there is greater desire to relieve negative effect and cue-craving was more pronounced [Table 4]. ${ }^{[21-23]}$

The hazards of smokeless form of tobacco are well documented like oral cancer, hypertension, cardio-vascular diseases..$^{[20,24,25]}$ Massive campaigns are required to decrease the incidence of tobacco related cancers and other diseases. ${ }^{[2]}$

In our study also while $43 \%$ were not aware about any harmful effects of smokeless tobacco, and $38 \%$ of women were aware that oral cancer can be the hazard of using mishri [Table 5].

Smoking, as well as use of smokeless tobacco during pregnancy, is harmful to the fetus along with mother. ${ }^{[27-29]}$ It has been reported that intrauterine growth retardation occurs due to the adverse effect of nicotine resulting in preterm deliveries and stillbirths, an important determinant of low birth weight during pregnancy is smoking 26-30. ${ }^{[30-32]}$ In our study, only $2 \%$ women knew its use during pregnancy can be responsible for low birth weight babies.

There is a need to make the rural women aware about hazardous effects of use of mishri through health education sessions to wean them out of this addiction, which is passed from one generation to the next as a tradition at an early age. ${ }^{[2]}$ The intervention in the schools, mahila-mandals and neighborhood in the form of awareness campaigns, and making available the other safe teeth cleaning powders will go a long way in reducing this menace.

\section{REFERENCES}

1. WHO. WHO Report on the Global Tobacco Epidemic 2011: Warning about the Dangers of Tobacco. Geneva: WHO; 2011.

2. Thakur JS, Garg R, Narain JP, Menabde N. Tobacco use: A major risk factor for non communicable diseases in South-East Asia region. Indian J Public Health 2011;55:155-60.

3. Shafey O, Ericksen M, Ross H, Mackay J. Tobacco Atlas. $3^{\text {rd }}$ ed. Atlanta: WHO; 2009.

4. The WHO FCTC Indicators. Global Tobacco Survey 2009. New Delhi, India: Regional Office for South East Asia; 2011.

5. Sieminska A, Jassem E. The many faces of tobacco use among women. Med Sci Monit 2014;20:153-62.

6. WHO. Technical Report Series, 773. Smokeless Tobacco Control-Report of WHO study Group. Geneva: WHO; 1983.

7. WHO. Tobacco or Health: A Global Status Report. Geneva: WHO; 1997.

8. WHO, Technical Report Series. Smokeless Tobacco Control-Report of WHO Study Group. Geneva: WHO, TRS; 1983. p. 773.

9. Krishnan VM. Tobacco and Areca Nut. New Delhi, India: Orient Longman; 2001. p. 17-8.

10. Tribhuvan RD, Kelkar A. Health issues of slum women. In: Tribhuvan RD, editor. Social Problems and Development Issues of Slum Women. Pune: Amruta Publishing Home; 1997. p. 67.

11. IARC Working Group on the Evaluation of Carcinogenic Risks to Humans; International Agency for Research on Cancer. Smokeless Tobacco; and SOME Tobacco-specific N-nitrosamines. Lyon, France, Geneva, Switzerland: World Health Organization, International Agency for Research on Cancer; distributed by WHO Press; c2007.

12. Pratinidhi A, Gandham S, Shrotri A, Patil A, Pardeshi S. Use of 'Mishri' a smokeless form of tobacco during pregnancy and its perinatal outcome. Indian J Community Med 2010;35:14-8.

13. Gupta PC, Subramoney S. Smokeless tobacco use and risk of stillbirth: A cohort study in Mumbai, India. Epidemiology 2006;17:47-51.

14. Gupta PC, Subramoney S. Smokeless tobacco use, birth weight, and gestational age: Population based, prospective cohort study of 1217 women in Mumbai, India. BMJ 2004;328:1538. Erratum in: BMJ 2010;340:c2191.

15. Verma RC, Chansoriya M, Kaul KK. Effect of tobacco chewing by mothers on fetal outcome. Indian Pediatr 1983;20:105-11.

16. Mehta A, Shukla S. Tobacco and pregnancy. J Obstet Gynaecol India 1990;40:156-60.

17. Pratinidhi AK, Ghate MM, Gupte AM. Relationship of use of mishri during pregnancy and weight of the newborn. J Obstet Gynnecol India 1995;1:72-7.

18. Schensul JJ, Nair S, Bilgi S, Cromley E, Kadam V, Mello SD, et al. Availability, accessibility and promotion of smokeless tobacco in a lowincome area of Mumbai. Tob Control 2013;22:324-30.

19. Srivastava M, Parakh P, Srivastava M. Predictors and prevalence of nicotine use in females: A village-based community study. Ind Psychiatry J 2010;19:125-9.

20. Connolly GN, Winn DM, Hecht SS, Henningfield JE, Walker B Jr, Hoffmann D. The reemergence of smokeless tobacco. N Engl J Med 1986;314:1020-7.

21. Brady KT, Back SE, Greenfield SF. Women and Addiction: A Comprehensive Handbook. New York: Guilford Press; 2009. 
22. Franklin TR, Napier K, Ehrman R, Gariti P, O'Brien CP, Childress AR. Retrospective study: Influence of menstrual cycle on cue-induced cigarette craving. Nicotine Tob Res 2004;6:171-5.

23. Pomerleau CS, Garcia AW, Pomerleau OF, Cameron OG. The effects of menstrual phase and nicotine abstinence on nicotine intake and on biochemical and subjective measures in women smokers: A preliminary report. Psychoneuroendocrinology 1992;17:627-38.

24. Bolinder GM, Ahlborg BO, Lindell JH. Use of smokeless tobacco: Blood pressure elevation and other health hazards found in a large-scale population survey. J Intern Med 1992;232:327-34

25. Spangler JG, Salisbury PL $3^{\text {rd }}$. Smokeless tobacco: Epidemiology, health effects and cessation strategies. Am Fam Physician 1995;52:1421-30, 3-4.

26. Gupta PC, Hamner J E, Murti PR. Control of Tobacco Related Cancer and other Diseases. c1992. p. P327. Available from: https://www.books. google.co.in/books?isbn=0195629612. [Last cited on 2014 Dec 12].

27. Krishnamurthy S, Joshi S. Gender differences and low birth weight with maternal smokeless tobacco use in pregnancy. J Trop Pediatr 1993;39:253-4.

28. Wen SW, Goldenberg RL, Cutter GR, Hoffman HJ, Cliver SP, Davis RO, et al. Smoking, maternal age, fetal growth, and gestational age at delivery Am J Obstet Gynecol 1990;162:53-8.

29. Butler NR, Goldstein H, Ross EM. Cigarette smoking in pregnancy: Its influence on birth weight and perinatal mortality. Br Med J 1972;2:127-30.

30. Lambers DS, Clark KE. The maternal and fetal physiologic effects of nicotine. Semin Perinatol 1996;20:115-26.

31. Wickström R. Effects of nicotine during pregnancy: Human and experimental evidence. Curr Neuropharmacol 2007;5:213-22.

32. Tobacco use in India: an evil with many faces, Cancer Patients Aid Association, Total management of cancer, American Cancer Society c2009, Inc. No.011286-Rev.06/10 India Project.

How to cite this article: Kakrani VA, Kulkarni PY, Khedkar DT, Bhawalkar JS. Perceptions and practices of smokeless tobacco use in the form of mishri among rural women above 10 years of age in Pune, Maharashtra, India. Int J Med Public Health 2015;5:173-8. Source of Support: Nil, Conflict of Interest: None declared.

\section{Author Help: Online submission of the manuscripts}

Articles can be submitted online from http://www.journalonweb.com. For online submission, the articles should be prepared in two files (first page file and article file). Images should be submitted separately.

1) First Page File:

Prepare the title page, covering letter, acknowledgement etc. using a word processor program. All information related to your identity should be included here. Use text/rtt/doc/pdf files. Do not zip the files.

\section{2) Article File:}

The main text of the article, beginning with the Abstract to References (including tables) should be in this file. Do not include any information (such as acknowledgement, your names in page headers etc.) in this file. Use text/rtt/doc/pdf files. Do not zip the files. Limit the file size to $1024 \mathrm{~kb}$. Do not incorporate images in the file. If file size is large, graphs can be submitted separately as images, without their being incorporated in the article file. This will reduce the size of the file.

3) Images:

Submit good quality color images. Each image should be less than $\mathbf{4 0 9 6} \mathbf{~ k b ~ ( 4 ~ M B ) ~ i n ~ s i z e . ~ T h e ~ s i z e ~ o f ~ t h e ~ i m a g e ~ c a n ~ b e ~ r e d u c e d ~ b y ~ d e c r e a s i n g ~}$ the actual height and width of the images (keep up to about 6 inches and up to about $1800 \times 1200$ pixels). JPEG is the most suitable file format. The image quality should be good enough to judge the scientific value of the image. For the purpose of printing, always retain a good quality, high resolution image. This high resolution image should be sent to the editorial office at the time of sending a revised article.

4) Legends:

Legends for the figures/images should be included at the end of the article file. 